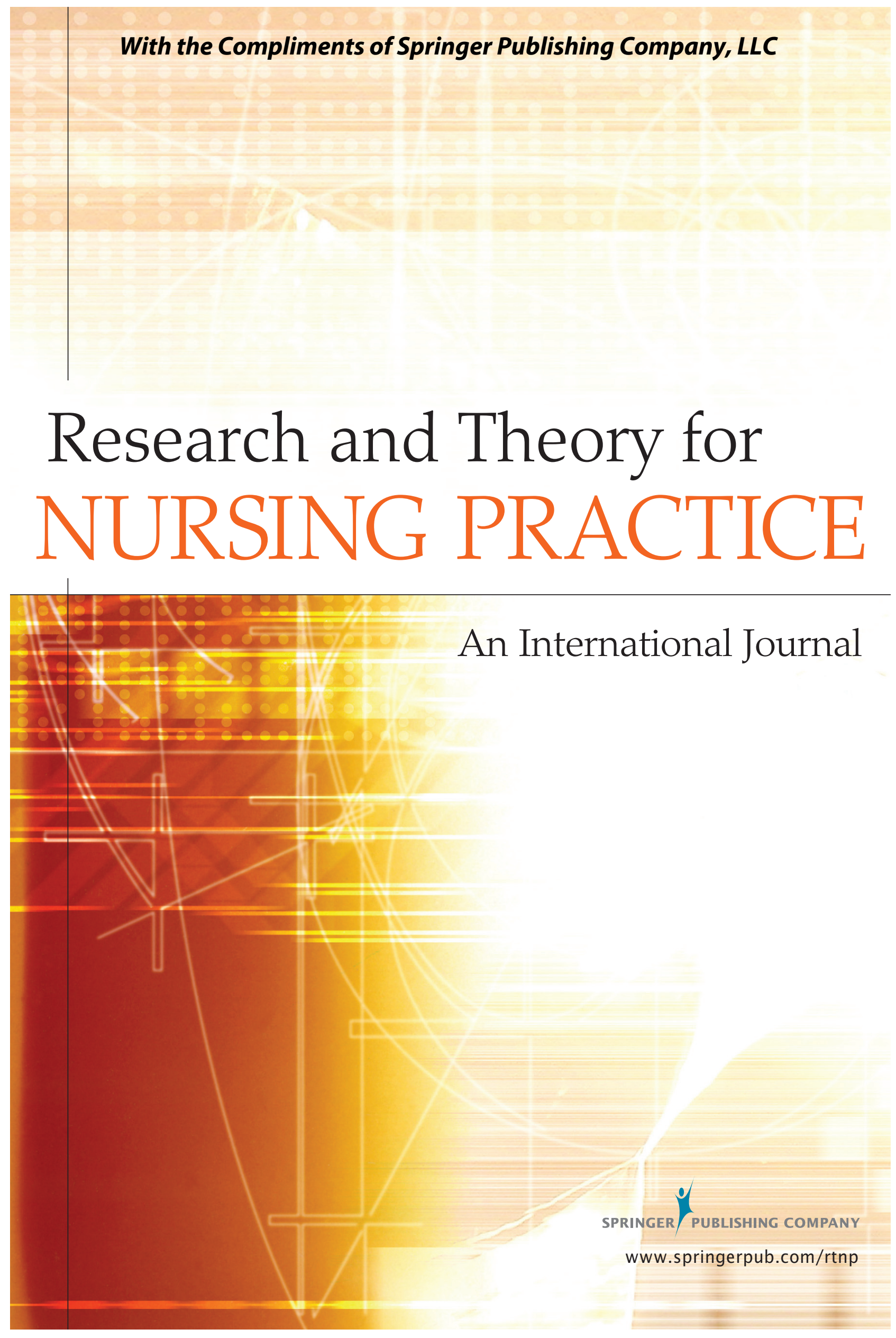


Research and Theory for Nursing Practice: An International Journal, Vol. 30, No. 3, 2016

\title{
Posttraumatic Stress Disorder Symptoms and Family Functioning in Adult Children Facing Parental Cancer: A Comparison Study
}

\author{
Ricardo J. Teixeira, PhD \\ M. Graça Pereira, PhD \\ University of Minho, School of Psychology, Braga, Portugal
}

\begin{abstract}
This study analyzed posttraumatic stress disorder (PTSD) symptoms and family functioning in a sample of adult children caregivers of cancer patients and in a group of adult children of nonchronically ill parents. Participants completed measures of family functioning and PTSD symptoms. The parental cancer group was subdivided into PTSD subgroups, and significant differences, on family functioning, were found. In the parental cancer group, the predictors of PTSD symptoms were being a woman and having an enmeshed or chaotic family functioning. Chaotic functioning mediated the relationship between family communication/satisfaction and PTSD symptoms, in the parental cancer group. Finally, there was a higher prevalence of PTSD symptoms in the parental cancer group, and participants with a probable PTSD diagnosis showed higher levels of family imbalance. This study shows that adult children facing parental cancer, who have a poorer family balance, may benefit from interventions that target family functioning.
\end{abstract}

Keywords: posttraumatic stress disorder (PTSD) symptoms; family functioning; parental cancer; caregivers

$\mathrm{R}$ esearch shows that almost half of family members of cancer patients experience levels of distress similar to patients, increasing strain on the family system (Schulz, Schultz, Schultz, \& Von Kerekjarto, 1996). Approximately $20 \%$ of primary family caregivers of adult cancer patients are the patients' adult children. These caregivers may experience high psychological distress associated with the diagnosis (threat of death of a loved one), as well as with multiple role demands (Mosher \& Danoff-Burg, 2005). In particular, adult children of parents with chronic illness have an increased risk of developing emotional and behavioral

\begin{tabular}{r}
\hline 212 (C) 2016 Springer Publishing Company \\
http://dx.doi.org/10.1891/1541-6577.30.3.212
\end{tabular}


problems than adult children of healthy parents. The risk, however, depends on individual and family variables related to the disease itself (Korneluk \& Lee, 1998).

Cancer is currently conceptualized as a possible precipitator of posttraumatic stress disorder (PTSD) symptoms (Diagnostic and Statistical Manual of Mental Disorders [4th ed.; DSM-IV-TR; American Psychiatric Association, 2000]), both in patients and in first-degree relatives. Considering cancer as a "seismic" event in the family, several studies have revealed a strong association between cancer and PTSD symptoms (Edwards et al., 2008). First-degree relatives of patients with cancer have significantly higher levels of intrusive cancer-related thoughts and avoidance, compared to relatives without a family history of cancer (Baider, Ever-Hadani, \& Kaplan De-Nour, 1999; Zakowski et al., 1997). In fact, 4\% of first-degree relatives showed symptoms consistent with a PTSD diagnosis, 7\% showed symptoms consistent with subclinical levels of potential PTSD that were probably cancer related (Lindberg \& Wellisch, 2004), and 53\% had considerable intrusive thoughts (Lerman et al., 1993).

Given the great variability in distress levels among first-degree relatives of cancer patients (Erblich, Bovbjerg, \& Valdimarsdottir, 2000; Lerman et al., 1993), it is important to assess the main predictors of their responses to stress. According to Wong, Looney, Michaels, Palesh, and Koopman (2006), when parents are diagnosed with cancer, the impact on their children may be sufficient to cause PTSD symptoms in adult children. The experience of caregiving is regarded as extremely stressful (Pinquart \& Sörensen, 2003). This distress results in profound changes in family members' life and behavior, including an increase in PTSD symptoms in patients' adult children and in other family members as well (Edwards et al., 2008; Huizinga et al., 2010).

Having as background the Circumplex Model of Marital and Family Systems (Olson, 2000), flexibility refers to the ability of a family system to change its power structure, role relationships, and relationship rules in response to a stressor. The extremes of flexibility are rigid and chaotic family systems. Both extremes are pathological, and the middle ground between the two is functional (Gorall, Tiesel, \& Olson, 2004). Another core dimension of this model is family cohesion, which is defined as the emotional bonding among family members. Extremely high cohesion involves overidentification with the family and is termed enmeshment. Extremely low involvement is defined as disengagement. Again, both extremes are considered to be pathological, whereas an average degree of cohesion is thought to be functional. An additional dimension of this model is communication among family members. Communication is defined as a positive skill that is used in the family system, which facilitates a change in levels of cohesion and flexibility in the family (Gorall et al., 2004). Family members who speak openly about their adverse experiences seem to have less difficulty in changing the structure and roles of the family when coping with disease and express lower levels of psychological distress (Schulz et al., 1996).

Physical and emotional pressures during the various stages of cancer may distort family relationships, even among families who cope well with the diagnosis and its effects (Carlson, Bultz, Speca, \& St-Pierre, 2000). In addition to the direct effects of cancer on families, the negative psychological changes in the patient may influence 
the family environment, resulting in a decrease in familial cohesion (Ben-Zur, 2001). Also, a high emotional expressiveness and cohesion in family relationships predict better psychological adjustment to cancer, in family members (Trask et al., 2003).

There are few studies with adult children of cancer patients, which include the perception of family context, that is, levels of cohesion, conflict, and organization and whose designs include comparison groups. Most literature fails to compare families of cancer patients with other groups, considering family functioning variables (Schulz et al., 1996; Weihs \& Reiss, 1996), and although there are some evidences linking family functioning to PTSD symptoms, especially in families with an experience of childhood cancer (Alderfer \& Kazak, 2006; Alderfer, Navsaria, \& Kazak, 2009), no studies to our knowledge have studied these variables in adult children caregivers of parents with cancer. Some studies, in different contexts, have reported a mediating effect of family functioning (Owen, Thompson, Shaffer, Jackson, \& Kaslow, 2009; Vanderlinden \& Vandereycken, 2000), but these processes were not studied in informal caregivers of cancer patients.

The aims of this study were to explore levels of family functioning and PTSD symptoms in adult children caregivers with parental cancer, comparing the results with a group of adult children without chronically ill parents; to find the predictors of PTSD symptoms; to analyze whether chaotic family functioning mediated the relationship between family communication/family satisfaction and PTSD symptoms, in the parental cancer group; and to find differences between groups in terms of PTSD symptom severity and family functioning.

\section{METHODS}

\section{DESIGN}

This was a cross-sectional, comparative study with two convenience samples (parental cancer group and a comparison group).

\section{SAMPLE SizE}

The sample was composed by 214 adult children caregivers of a parent with cancer. Inclusion criteria required participants to be $\geq 18$ years old; have a parent receiving chemotherapy; accompany the parent to the hospital for treatment; and not suffer from oncological, psychiatric, or neurological disease. The comparison group included 78 adult children without a chronically ill parent. This group was recruited at a major public university. Sample characteristics are shown in Table 1.

\section{Procedure and Data Collection}

The research design was approved by the ethic committees of three general hospitals and a state university in Northern Portugal. Participation was voluntary. The parental cancer group was composed of adult children who, during the period of data collection, accompanied the parent diagnosed with cancer to chemotherapy. 
TABLE 1. Sample Characteristics ( $M$ and $S D$ or $N$ and Percentages)

\begin{tabular}{lcc}
$\begin{array}{l}\text { Demographic } \\
\text { Characteristics }\end{array}$ & $\begin{array}{c}\text { Adult Children Caregivers } \\
(N=214)\end{array}$ & $\begin{array}{c}\text { Comparison Group } \\
(N=78)\end{array}$ \\
\hline Age & $33.12(9.16)$ & $32.23(9.83)$ \\
Gender & $158(26 \%)$ & $59(76 \%)$ \\
$\quad$ Female & $56(74 \%)$ & $19(24 \%)$ \\
$\quad$ Male & & $37(47 \%)$ \\
Marital status & $114(53 \%)$ & $41(53 \%)$ \\
$\quad$ Without a partner & $100(47 \%)$ & $42(22 \%)$ \\
$\quad$ With a partner & & $58(78 \%)$ \\
Education & $134(63 \%)$ & \\
$\quad$ Less than high school & $80(37 \%)$ & \\
$\quad$ More than high school & & \\
\hline
\end{tabular}

\section{INSTRUMENTS}

Family Adaptability and Cohesion Evaluation Scales-4th Version. The Family Adaptability and Cohesion Evaluation Scales-4th Version (FACES-IV; Olson, 2011) is a self-report measure that assesses family functioning according to the Circumplex Model of Marital and Family Systems. It comprises 42 items on a Likert-type scale divided into six scales: (a) two balanced assessing centralmoderate areas-cohesion (e.g., "family members are involved in each others lives" and "family members feel very close to each other") and flexibility (e.g., "our family tries new ways of dealing with problems" and "parents equally share leadership in our family" and (b) four unbalanced-enmeshed (e.g., "we spend too much time together" and "family members feel pressured to spend most free time together"), disengaged (e.g., "we get along better with people outside our family than inside" and "family members seem to avoid contact with each other when at home"), rigid (e.g., "there are strict consequences for breaking the rules in our family" and "there are clear consequences when a family member does something wrong"), and chaotic (e.g., "we never seem to get organized in our family" and "it is hard to know who the leader is in our family"), assessing the lower and the upper ends of cohesion and flexibility. The two balanced scales assess normal functioning, whereas the remaining scales assess problematic functioning. FACES-IV also yields ratio scores, which represent the level of functionality versus dysfunctionality of the family. Three ratio scores can be obtained: cohesion, flexibility, and total family functioning. The higher the ratio scores, over 1 , the more balanced or healthy the system is (Olson, 2010). The FACES-IV scales proved to be valid, reliable, and discriminatory among both problematic and nonproblematic families, and the range of reliability in the six scales is between .78 and .90 (Olson, 2011). 
Family Communication Scale. The Family Communication Scale (FCS; Olson \& Barnes, 2004), a 10-item (e.g., "family members are satisfied with how they communicate with each other" and "family members are very good listeners") questionnaire, was used. Family communication is defined as the systemic capacity for positive communication within marital or family systems and is seen as a facilitator that can alter the levels of cohesion and flexibility. Higher scores (summed results) indicate that family members are pleased with the communication between them. In the original study, the internal consistency was .90 (test-retest $=.86$ ).

Family Satisfaction Scale. The Family Satisfaction Scale (FSS; Olson, 2004), a 10-item (e.g., "the degree of closeness between family members" and "your family's ability to cope with stress") questionnaire, was used. Family satisfaction is defined as the degree to which family members feel happy and fulfilled with each other. Higher scores indicate that members are satisfied with their family. In the original study, the internal consistency was .93 (test-retest $=.85$ ).

Impact of Event Scale-Revised. The Impact of Event Scale-Revised (IES-R; Pereira \& Teixeira, 2011; Weiss \& Marmar, 1997) that assesses PTSD symptoms. This is a 22-item (e.g., "pictures about it popped into my mind" and "any reminder brought back feelings about it") self-report measure of current subjective distress related to a specific adverse/traumatic event. The exploratory factor analysis with the present sample revealed a factor structure very similar to the original study, explaining $56.71 \%$ of the total variance. The Portuguese-adapted version maintained the original 22 items. However, for this study, only the total score was used. Participants in the parental cancer group were instructed to focus only on their caregiving experiences; the comparison group was asked to rate items regarding their most stressful life event. A cutoff of 33 was used for a probable diagnosis of PTSD (Creamer, Bell, \& Failla, 2003; Wang et al., 2011).

\section{DATA AnAlYsis}

Correlations among variables were performed using Pearson correlation. Group differences for family functioning were performed through multivariate analysis of covariance (MANCOVA), and for PTSD symptoms through analysis of covariance (ANCOVA), controlling for level of education. To find the predictors of PTSD symptoms, a hierarchical multiple regression analysis was conducted. Demographic variables (gender and age) were entered in Step 1, and family functioning (FACES-IV subscales), family satisfaction (results on FSS) and communication (results on FCS), in Step 2. Mediating effects of family functioning on PTSD symptoms were tested using a bootstrap approach, designed to estimate the sampling distribution of the indirect effects. This procedure assumes that the distribution of the measured variables approximates that of the population, while it avoids making the frequent assumption that the indirect effect is distributed normally. For this purpose, the SPSS syntax provided by Preacher and Hayes (2004) was used. The bootstrapping method with 5,000 resamples was performed to test the estimate of indirect effects. This estimate is determined to be of a significant size if zero does not fall between the confidence intervals (CIs) of the bootstrap estimate, at $p<.05$ (Preacher \& 
Hayes, 2004). Differences between groups, considering the PTSD symptoms cutoff, in terms of severity, were first analyzed with the chi-square, and then with a twoway MANCOVA. Finally, a multivariate analysis of variance (MANOVA) was used to analyze differences in PTSD versus non-PTSD symptom subgroups in the parental cancer sample, considering family functioning variables.

\section{RESULTS}

\section{PARTICIPANTS}

As previously reported, the parental cancer group consisted of 214 participants and the comparison group consisted of 78 participants. Concerning the first group, parents' tumor sites were heterogeneous, and no cases with both parents in treatment were registered. Regarding clinical data, $61 \%$ of caregivers reported to provide care for less than 1 year; $60 \%$ reported the parent's disease duration to be less than 1 year, and $21 \%$ of adult children perceived the parent in treatment as completely dependent on their caregiving. Comparatively, the groups showed no significant differences in terms of gender, $\chi^{2}(1)=.098, p=.754$, age, $t(290)=.721, p=.472$, and marital status, $\chi^{2}(1)=.779, p=.377$. However, there were significant differences in education, $\chi^{2}(1)=11.666, p=.003$, which were accounted for in the statistical analysis.

\section{Relationships Among VARIABles}

Analyses were conducted to examine intercorrelations among FACES-IV, FCS, FSS, and IES-R, in the sample of adult children caregivers. As shown in Table 2, convergent validity of the FACES-IV Portuguese version showed strong correlations with most of the validation scales (between -.590 and .590 with the FCS and between -.510 and .542 with the FSS) except for the enmeshed (-.049 and .011) and rigid $(-.086$ and -.072$)$ scales. These two seem to be "independent" from other scales, although they were correlated (.36). Finally, PTSD symptoms correlated with the enmeshed (.258) and chaotic (.142) subscales.

\section{Differences Between Groups on Posttraumatic Stress Disorder AND FAMILY FunCTIONING}

As displayed in Table 3, the group of adult children caregivers showed a significantly higher incidence of PTSD symptoms than the group of adult children without chronically ill parents, $F(1,289)=20.364, p=.000$. In terms of family functioning, the first group showed significantly lower levels of balanced cohesion, $F(1,289)=$ $4.463, p=.035$, and flexibility, $F(1,289)=7.112, \mathrm{p}=.008$, and more enmeshment, $F(1,289)=9.044, p=.003$.

Although the means for both groups on FACES-IV ratios were all above 1, the adult children caregivers group revealed significantly lower cohesion, $F(1,289)=$ $10.206, p=.002$, flexibility, $F(1,289)=11.362, p=.001$, and the total ratio, $F(1,289)=$ $12.307, p=.001$, means when compared to the comparison group, indicating a 


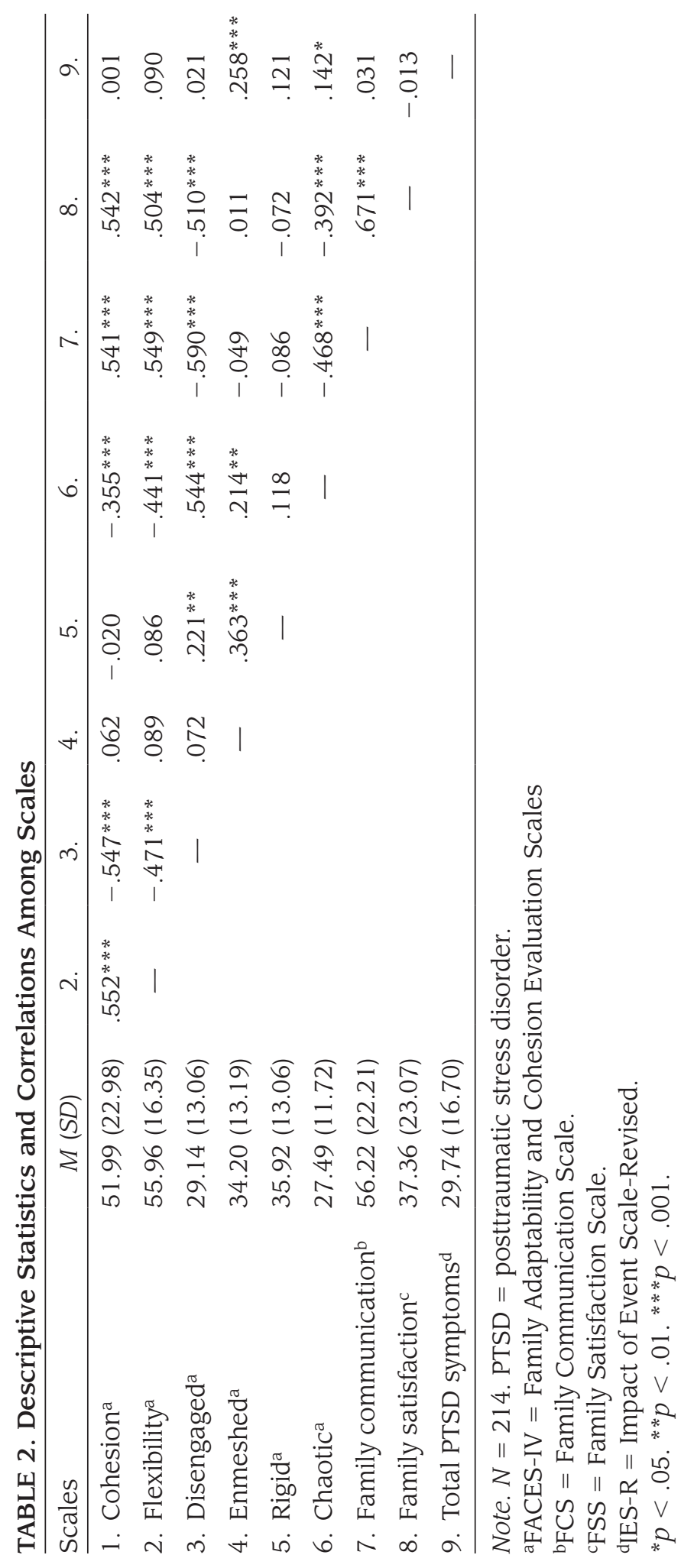


TABLE 3. Differences Between Parental Cancer and Comparison Groups $(M$ and $S D)$

\begin{tabular}{lccc}
\hline Variables & $\begin{array}{c}\text { Parental Cancer } \\
\text { Group }(N=214)\end{array}$ & $\begin{array}{c}\text { Comparison Group } \\
(N=78)\end{array}$ & $F(1,289)$ \\
\hline PTSD symptoms $^{\mathrm{a}}$ & $3.87(2.16)$ & $2.61(1.76)$ & $20.374^{* * *}$ \\
Family functioning $^{\mathrm{b}}$ & & & \\
$\quad$ Cohesion & $51.99(22.98)$ & $58.64(22.96)$ & $4.463^{*}$ \\
$\quad$ Flexibility & $55.96(16.35)$ & $62.23(20.04)$ & $7.112^{* *}$ \\
Disengaged & $29.14(13.06)$ & $27.30(11.93)$ & 0.921 \\
Enmeshed & $34.20(13.19)$ & $28.85(10.18)$ & $9.044^{* *}$ \\
Rigid & $35.92(13.06)$ & $35.30(11.38)$ & 0.032 \\
Chaotic & $27.49(11.72)$ & $27.35(9.90)$ & 0.027 \\
$\quad$ Cohesion ratio & $1.58(0.42)$ & $1.80(0.60)$ & $10.206^{* *}$ \\
$\quad$ Flexibility ratio & $1.32(0.28)$ & $1.48(0.44)$ & $11.362^{* * *}$ \\
$\quad$ Total ratio & $1.45(0.32)$ & $1.64(0.49)$ & $12.307^{* * *}$ \\
Family communication $^{c}$ & $56.22(22.21)$ & $58.71(21.76)$ & 0.814 \\
Family satisfaction $^{\mathrm{d}}$ & $37.46(23.07)$ & $40.34(25.51)$ & 0.630 \\
\hline
\end{tabular}

Note. PTSD $=$ posttraumatic stress disorder.

aIES-R = Impact of Event Scale-Revised.

bFACES-IV = Family Adaptability and Cohesion Evaluation Scales.

${ }^{\mathrm{c}} \mathrm{FCS}=$ Family Communication Scale.

${ }^{\mathrm{d}} \mathrm{FSS}=$ Family Satisfaction Scale.

${ }^{*} p<.05 .{ }^{* *} p<.01 .{ }^{* * *} p<.001$.

lower family balance. Finally, and contrary to expected, there were no significant differences between groups in terms of family communication, $F(1,289)=.814$, $p=.368$, and family satisfaction, $F(1,289)=.630, p=.428$.

\section{Predictors of Posttraumatic Stress Disorder Symptoms}

The regression model for the parental cancer group explained 13\% of the observed variance, $F(10,203)=2.923, p<.01$. Being a woman predicted higher levels of PTSD symptoms $(p=.013)$ but not age $(p=.693)$. When controlling for these variables, family functioning's characterized for higher enmeshment $(p=.008)$ and chaos $(p=.033$; i.e., only the enmeshment and chaotic FACES-IV scales) predicted higher PTSD symptoms in adult children with parental cancer. Multicollinearity was not a problem because the predictor variables were not correlated more than .80 , the tolerance was between .42 and .96, and the variance inflation factor (VIF) between 1.104 and 2.363 (Field, 2009). Concerning the comparison group, the regression model was not significant, $F(10,67)=1.649, p=.059$. Table 4 reports only the results for the parental cancer group. 
TABLE 4. Hierarchical Multiple Regression for PTSD Symptoms in the Parental Cancer Group (Final Model)

\begin{tabular}{lccc}
\hline Variables & $B$ & $S E B$ & $\beta$ \\
\hline Step 1 & & & \\
$\quad$ Gender & .846 & .339 & $.172^{*}$ \\
Age & -.006 & .016 & -.026 \\
Step 2 & & & \\
$\quad$ Cohesion & & .009 & -.113 \\
Flexibility $^{\mathrm{b}}$ & -.011 & .012 & .142 \\
Disengaged $^{\mathrm{b}}$ & -.019 & .016 & -.029 \\
Enmeshed $^{\mathrm{b}}$ & -.005 & .012 & $.197^{* *}$ \\
Rigid $^{\mathrm{b}}$ & .032 & .012 & .044 \\
Chaotic $^{\mathrm{b}}$ & .007 & .016 & $.181^{*}$ \\
Communication $^{\mathrm{c}}$ & .033 & .010 & .135 \\
Satisfaction $^{\mathrm{d}}$ & .013 & .009 & -.061 \\
\hline
\end{tabular}

Note. $N=214 ; R^{2}=.025$ for Step $1, p=.066 ; \Delta R^{2}=.100$ for Step $2, p<.01$; $R^{2}=.126$, Adjusted $R^{2}=.083$. PTSD = posttraumatic stress disorder.

${ }^{\mathrm{a}} 0=$ male, $1=$ female.

${ }^{b}$ FACES-IV = Family Adaptability and Cohesion Evaluation Scales.

${ }^{\mathrm{C} F C S}=$ Family Communication Scale.

${ }^{\mathrm{d}} \mathrm{FSS}=$ Family Satisfaction Scale.

${ }^{*} p<.05 .{ }^{* *} p<.01$.

\section{MEDiation AnALYsis}

To test that unbalance family indicators influence the relationship between family communication/family satisfaction and PTSD symptoms, the analysis was focused on previously found unbalance predictors of PTSD symptoms (Table 5), for the parental cancer group, that is, enmeshed and chaotic family functioning. The results of regression analyses showed that communication and satisfaction (the independent variables [IVs] in the mediation analyses) did not predict PTSD symptoms (the dependent variable [DV] in the mediation analyses) in the caregiver group; however, an association between IV and DV is not essential for mediation to occur (Hayes, 2009). The mediating effect of the enmeshed familiar type analysis was discarded because bootstrap 95\% confidence intervals (CIs) indicated that the indirect effect of the independent variables family communication, $\mathrm{a} \times \mathrm{b}$ (point estimate) $=-.0012$, $95 \%$ CI $[-.0052, .0027]$, and family satisfaction, $\mathrm{a} \times \mathrm{b}$ (point estimate) $=.0003,95 \%$ CI $[-.0030, .0040]$, were nonsignificant, that is, zero was in the $95 \%$ CIs.

The mediating analysis of the chaotic functioning revealed that for family communication, $\mathrm{a} \times \mathrm{b}$ (point estimate) $=-.0091,95 \% \mathrm{CI}[-.0170,-.0019]$, and family satisfaction, $\mathrm{a} \times \mathrm{b}$ (point estimate) $=-.0060,95 \% \mathrm{CI}[-.0117,-.0005]$, the indirect effects were significantly different from zero at $p<.05$, that is, significant 
TABLE 5. Posttraumatic Stress Disorder Severity Differences in the Parental Cancer Group ( $M$ and $S D$ Reported) for Family Functioning Scales

\begin{tabular}{lccc}
\hline & \multicolumn{3}{c}{ PTSD Severity $^{\mathrm{a}}$} \\
\cline { 2 - 4 } Scales & $\begin{array}{c}\text { With Probable PTSD } \\
(n=86)\end{array}$ & $\begin{array}{c}\text { Without Probable } \\
\text { PTSD }(n=128)\end{array}$ & $F(1,212)$ \\
\hline Cohesion $^{\mathrm{b}}$ & $49.76(22.74)$ & $53.49(23.12)$ & 1.353 \\
Flexibility $^{\mathrm{b}}$ & $54.90(18.07)$ & $56.67(15.11)$ & 0.598 \\
Disengaged $^{\mathrm{b}}$ & $31.67(13.93)$ & $27.44(12.21)$ & $5.501^{*}$ \\
Enmeshed $^{\mathrm{b}}$ & $36.93(15.56)$ & $32.36(11.02)$ & $6.302^{*}$ \\
Rigid $^{\mathrm{b}}$ & $37.50(13.18)$ & $34.86(12.93)$ & 2.099 \\
Chaotic $^{\mathrm{b}}$ & $30.26(13.57)$ & $25.63(9.91)$ & $8.317^{* *}$ \\
Family communication $^{\mathrm{c}}$ & $54.56(24.50)$ & $57.34(20.56)$ & 0.801 \\
Family satisfaction $^{\mathrm{d}}$ & $34.34(21.74)$ & $39.56(23.77)$ & 2.647 \\
\hline
\end{tabular}

Note. $N=214$. PTSD = posttraumatic stress disorder.

${ }^{a}$ Considering the cutoff point on the Impact of Event Scale-Revised (IES-R).

${ }^{b}$ FACES-IV = Family Adaptability and Cohesion Evaluation Scales.

${ }^{\mathrm{c}} \mathrm{FCS}=$ Family Communication Scale.

${ }^{\mathrm{d}} \mathrm{FSS}=$ Family Satisfaction Scale

${ }^{*} p<.05 .{ }^{* *} p<.01$.

indirect effects of IVs (family communication/satisfaction) on DV (PTSD symptoms) were found, through the mediator (chaotic family functioning; Figure 1). Although significant, the effect sizes of these indirect effects were small (.06 for family communication and .05 for family satisfaction) (Preacher \& Kelley, 2011; see Figure 1).

\section{PostTraumatic Stress disorder SeVerity Differences IN THE Parental Cancer Group for Family Functioning}

Results revealed that, considering the cutoff on the IES-R, there was a higher prevalence of PTSD-probable cases in the group of parental cancer, compared to the comparison group, $\chi^{2}(1, N=292)=19.400, p<.001, O R=4.6$, specificity $=87$, sensitivity $=40$. Contrary to expected, the interaction between groups and severity of PTSD symptoms was not significant, Wilks's lambda $=.982, F(8,280)=.657, p=$ .729 , and no significant effects for any of the family variables were found. Therefore, given the greater incidence of probable PTSD cases in the parental cancer group (40\% vs. 13\%), family functioning differences, considering PTSD grouping, were analyzed. Results are displayed in Table 5.

Caregivers with probable PTSD scored significantly higher on the disengaged $(p=.020)$, enmeshed $(p=.013)$, and chaotic $(p=.004)$ scales, indicating greater family imbalance. There were no significant differences in the balanced scales. 


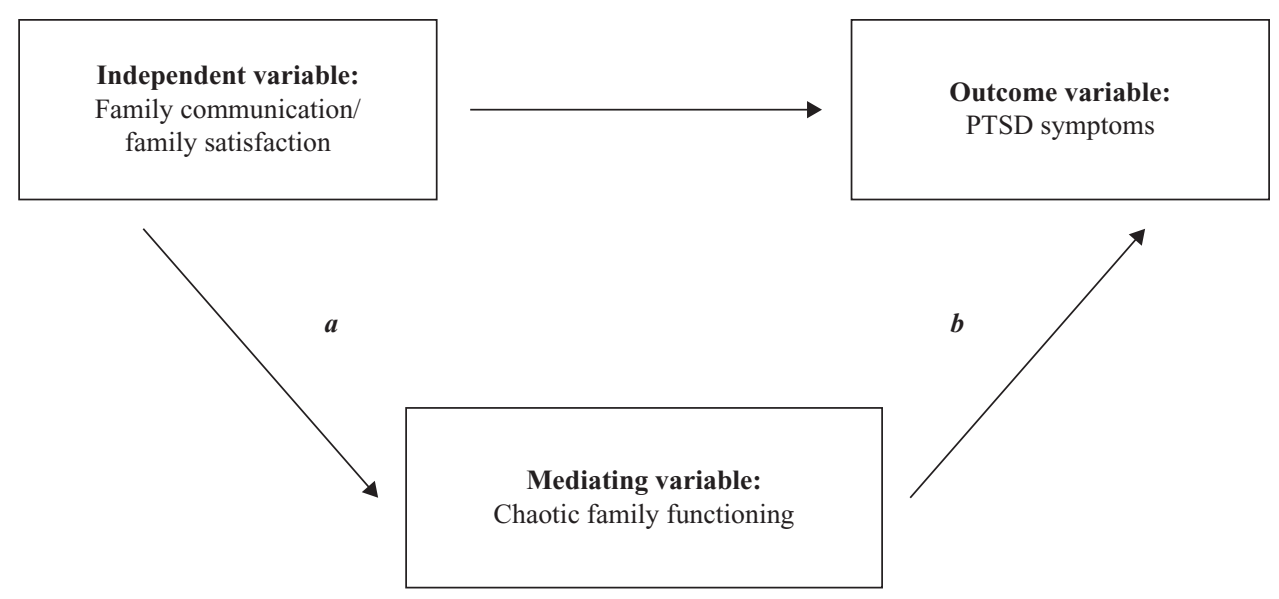

Figure 1. Representation of the mediating effects of chaotic family functioning between family communication and family satisfaction and PTSD symptoms in the parental cancer group $(N=214)$. PTSD $=$ posttraumatic stress disorder.

\section{DISCUSSION}

This study revealed significant differences between adult children caregivers with parental cancer and a comparison group, in self-reported family functioning and PTSD symptoms. When contrasted, the adult children caregivers showed significantly lower balanced family cohesion $(p=.035)$ and flexibility $(p=.008)$ as well as significantly higher family enmeshment $(p=.003)$. From a Circumplex Model's perspective, the literature reports that difficulties in cohesion may potentiate psychological problems in adulthood (Cummings \& Davies, 1992). Thus, lower levels of cohesion may reflect a lack of emotional bonding/togetherness of adult children with parental cancer toward other family members. Similarly, lower flexibility can reflect an inhibition of the adult children's family to manage both stability and change. This lower balance is also expressed in the lower circumplex ratios showed by the parental cancer group. Circumplex Model stresses that families may move toward enmeshment after a diagnosis of a chronic disease (Marsac \& Alderfer, 2011). In the present sample, enmeshment $(p=.003)$ persists when compared to families without a chronically ill parent, what could be representative of a difficulty to manage inappropriate closeness of family members.

Previous literature supports family balance as a significant influence on PTSD symptoms. It has been shown that the association between family cohesion and flexibility with trauma is negative (Rutledge, Davies, \& Davies, 1994) and that individuals from families with higher levels of cohesion, flexibility, and communication reported lower distress and PTSD symptoms (Uruk, Sayger, \& Cogdal, 2007). The present results show that adult children caregivers of parents with cancer appear to have enhanced levels of PTSD symptoms, when contrasted with a comparison group $(p=.000)$.

Cancer may be felt as an adverse/traumatic event. For example, adolescents with a history of cancer who met criteria for lifetime PTSD saw their families as significantly more chaotic than those with a history of cancer who did not have 
PTSD (Pelcovitz et al., 1998). With adult children, this study is the first one examining whether PTSD symptoms can be predicted by their family's functioning because they perceive it. This study shows that being a woman $(p=.013)$, and having a more enmeshed $(p=.008)$ and chaotic $(p=.033)$ family functioning, predicts higher PTSD symptoms in adult children with parental cancer. However, these results need to be considered cautiously because the variance explained was only $13 \%$, and they could be interpreted either as the consequence of exaggerated bonding between family members or as a result of the establishment of the lenient rules (higher tolerance) within the family, especially for female caregivers. On the other hand, as previously reported, families may move toward enmeshment after a diagnosis of a chronic illness (Marsac \& Alderfer, 2011). Birmes et al. (2009) state that, within the context of a shattering event affecting all members of the same family, feelings of belonging to an enmeshed (or closely knit) family may act as a protective factor. This is an issue that needs further research in future studies on family functioning and stressful events. In the present sample of parental cancer, enmeshment was still present when compared to families without a chronically ill parent, which could be representative of a difficulty in managing inappropriate closeness of family members.

Within the parental cancer sample, unbalance family indicators, specifically a chaotic functioning, showed a mediating effect (using a bootstrap approach) on the relationship between family communication/satisfaction and PTSD symptoms. Enmeshed functioning (a significant predictor of PTSD symptoms in the regression model) did not emerge as a significant mediator; however, chaotic functioning was a significant mediator. Despite the low magnitudes of the indirect effects, the effect size of family communication via chaotic functioning was slightly greater than that of family satisfaction ( 0.06 vs. 0.05$)$. This finding suggests that a chaotic family functioning may play a greater role in mediating the indirect effect of family communication on PTSD symptoms, when compared to the indirect effect of family satisfaction on PTSD symptoms. Previous literature supports our hypothesis that perceived family environment might be an important mediating variable in determining psychological suffering (Vanderlinden \& Vandereycken, 2000; Warner, Mufson, \& Weissman, 1995). This study is the first to provide evidence for the hypothesis that unbalance family flexibility, especially in the chaotic extreme, mediates the relation between facilitators of family functioning (communication and satisfaction) and PTSD symptoms. The results emphasize that a chaotic family functioning interfere indirectly in the association between difficulties in family communication and satisfaction and higher levels of PTSD symptoms in adult children dealing with parental cancer. Also, the present results are in accordance with previous studies showing that in families dealing with cancer, communication patterns are considered an important factor prompting the ways in which the offsprings are affected (Lewandowski, 1992). In fact, in a parental cancer context, a more open communication with the healthy parent (mostly fathers) was related to fewer PTSD symptoms in daughters (Huizinga et al., 2010). Overall, flexibility and cohesion in families facing cancer appear to be consistent with norms (Kazak, Christakis, Alderfer, \& Coiro, 1994; Manne et al., 1995). However, some patterns of either very high or very low flexibility scores have been found (Horwitz \& Kazak, 1990; Kazak \& Meadows, 1989). As mentioned earlier, it seems normative for families, in response 
to a major stressor, to function at one of the extremes without harmful effects. An extreme form of family functioning may serve a purpose for a limited time, but if it persists, may become problematic (Olson, 1993).

Differences of probable PTSD and non-PTSD groups within the sample of adult children caregivers were also performed. As reported, there was an almost five times higher likelihood of probable PTSD cases in this sample, when compared with the comparison group, although there was a nonsignificant interaction between groups and PTSD severity. This result may be explained by the reduced number of participants in the comparison group that present symptom severity above the cutoff for PTSD $(n=10)$. Thereby, family functioning differences in terms of PTSD for the parental cancer group were studied separately. Results revealed that the subgroup of caregivers with a probable PTSD diagnosis showed greater enmeshment $(p=.013)$, disengagement $(p=.020)$, and chaotic $(p=.004)$ family functioning, when compared with the subgroup below the cutoff. Linkages between poor family functioning and PTSD symptoms have been found in other studies (Navia \& Ossa, 2003; Ozono et al., 2007), underlying that family closeness should be of particular concern in the context of traumatic stress. The present findings add data to the hypothesis that a poorer family functioning may contribute to adult children with parental cancer to develop PTSD symptoms.

The findings from this study must be considered within the scope of its limitations as working hypotheses, for future studies. Given the correlational cross-sectional nature of this study, a causal link between family functioning and PTSD symptoms cannot be made. Longitudinal studies are needed to assess the direction of effect between family functioning, in oncology contexts, and PTSD symptoms. Some internal consistencies of FACES-IV scales were below .70 (Nunnally \& Bernstein, 1994), two in the parental cancer group (both .67) and three in the comparison group (.65, .66 , and .67), raising questions about the reliability and validity of these subscales in these samples. Nevertheless, because their range is between .65 and .70 , alphas can be considered "minimally acceptable" (DeVellis, 1991). Furthermore, these scales (specially the enmeshed and the rigid) showed lower alphas in the original study as well (Olson, 2011) and in other investigations (Baiocco, Cacioppo, Laghi, \& Tafà, 2013; Marsac \& Alderfer, 2011; Mirnics, Vargha, Tóth, \& Bagdy, 2010). Considering that reliability depends on sample size (Duhachek, Coughlan, \& Iacobucci, 2005), further studies with higher sample sizes are needed.

It is important to stress that the present findings do not imply that chaotic family functioning is the only mediator of the relationship between family communication/ satisfaction and PTSD symptoms because it was only a partial mediator, leaving ample room for other constructs to explain the central relationship. Interpretation of results of mediating analyses on cross-sectional data must always be cautious. However, the presence of a hypothesis grounded in the theoretical literature, and partially supported by previous empirical studies, provides a sufficiently compelling case for the mediating model that was conducted. Again, future studies should employ a longitudinal design to clarify the direction of causation.

A major strength of this study was the inclusion of a comparison group that showed adult children caregivers of cancer patients suffer more psychological distress and that their family systems seem to suffer changes that undermine their family balance. 
Knowing that adult children dealing with a parent's cancer are more distressed, and their family dynamics more disrupted than adult children without chronically ill parents, is undoubtedly important. However, future studies should include comparison groups of adult children of parents with a chronic disease or condition such as arthritis or type 2 diabetes, where adult children may be relied on for instrumental support but for whom the existential aspects are not as paramount. Also, this study should be replicated with a bigger sample size in the comparison group. Such an analysis might shed light on the particular challenges associated with a cancer diagnosis in the family and/or specific directions that clinicians should take in relation to intervening with families where a parent has cancer. Further investigations should also evaluate PTSD symptoms in the parent with cancer as well because literature supports that parents' symptoms mediate the offspring's response to adverse/traumatic events (Hoven et al., 2005). This cross-information could be important not only for diagnostic but also for therapeutic purposes as well (Shemesh et al., 2005). This study found that family functioning was one of the variables, together with gender, that predicted stress reactions in adult offspring of cancer patients, explaining 13\% of the variance and, therefore, future studies should take in consideration other important clinical variables regarding parental cancer as well.

Given the associations between PTSD symptoms and family functioning, these data suggest that adult children with parental cancer and their families may benefit from prevention and intervention programs that target family functioning as an outcome. Literature shows that lower distress is found in children of families that are not rigid or chaotic (Blanchard, Albrecht, \& Ruckdeschel, 1997). As a result, family interventions, particularly in chaotic families, should be provided to help them better adapt to parental cancer. Therefore, it would be important for professionals, when screening for stress, to include an assessment of family functioning, as well. Interventions should follow the hypothesis that through healthy relationships within the family, these adult children may learn healthy ways of coping with cancer-related distress and not persist in extreme family functioning. In order for adult children to deal effectively with parental cancer, acceptance of the illness is fundamental. For this to occur, balanced levels of family flexibility become important.

In conclusion, although differences were found in family functioning between groups with parental cancer and without chronically ill parents, and new considerations were achieved for PTSD concerns in the parental cancer group, additional work is needed regarding the identification of factors that predict those at highest risk for PTSD symptoms and overall psychological suffering.

\section{REFERENCES}

Alderfer, M. A., \& Kazak, A. E. (2006). Family issues when a child is on treatment for cancer. In R. Brown (Ed.), Pediatric hematology/oncology: A biopsychosocial approach (pp. 53-74). New York, NY: Oxford University Press.

Alderfer, M. A., Navsaria, N., \& Kazak, A. E. (2009). Family functioning and posttraumatic stress disorder in adolescent survivors of childhood cancer. Journal of Family Psychology, $23,717-725$ 
American Psychiatric Association. (2000). Diagnostic and statistical manual of mental disorders (4th ed., text rev.). Washington, DC: Author.

Baider, L., Ever-Hadani, P., \& Kaplan De-Nour, A. (1999). Psychological distress in healthy women with familial breast cancer: Like mother, like daughter? International Journal of Psychiatry in Medicine, 29, 411-420.

Baiocco, R., Cacioppo, M., Laghi, F., \& Tafà, M. (2013). Factorial and construct validity of FACES IV among Italian adolescents. Journal of Child and Family Studies, 22, 962-970.

Ben-Zur, H. (2001). Your coping strategy and my distress: Inter-spouse perceptions of coping and adjustment among breast cancer patients and their spouses. Families, Systems, \& Health, 19, 83-94.

Birmes, P., Raynaud, J. P., Daubisse, L., Brunet, A., Arbus, C., Klein, R., . . Schmitt, L. (2009). Children's enduring PTSD symptoms are related to their family's adaptability and cohesion. Community Mental Health Journal, 45, 290-299.

Blanchard, C. G., Albrecht, T. L., \& Ruckdeschel, J. C. (1997). The crisis of cancer: Psychological impact on family caregivers. Oncology, 11, 189-194.

Carlson, L. E., Bultz, B. D., Speca, M., \& St-Pierre, M. (2000). Partners of cancer patients: Part II. Current psychosocial interventions and suggestions for improvement. Journal of Psychosocial Oncology, 18, 33-43.

Creamer, M., Bell, R., \& Failla, S. (2003). Psychometric properties of the Impact of Event ScaleRevised. Behaviour Research and Therapy, 41, 1489-1496.

Cummings, E. M., \& Davies, P. T. (1992). Parental depression, family functioning, and child adjustment: Risk factors, processes, and pathways. In D. Cicchetti \& S. L. Toth (Eds.), Developmental perspectives on depression (pp. 283-322). New York, NY: University of Rochester Press.

DeVellis, R. F. (1991). Scale development: Theory and applications. Newbury Park, CA: Sage.

Duhachek, A., Coughlan, A. T., \& Iacobucci, D. (2005). Results on the standard error of the coefficient alpha index of reliability. Marketing Science, 24, 294-301.

Edwards, L., Watson, M., St. James-Roberts, I., Ashley, S., Tilney, C., Brougham, B., . . Romer, G. (2008). Adolescent's stress responses and psychological functioning when a parent has early breast cancer. Psycho-oncology, 17, 1039-1047.

Erblich, J., Bovbjerg, D. H., \& Valdimarsdottir, H. B. (2000). Looking forward and back: Distress among women at familial risk for breast cancer. Annals of Behavioral Medicine, 22, 53-59.

Field, A. (2009). Discovering statistics using SPSS (2nd ed.). London, United Kingdom: Sage.

Gorall, D. M., Tiesel, J., \& Olson, D. H. (2004). FACES-IV: Development and validation. Minneapolis, MN: Life Innovations.

Hayes, A. F. (2009). Beyond Baron and Kenny: Statistical mediation analysis in the new millennium. Communication Monographs, 76, 408-420.

Horwitz, W. A., \& Kazak, A. E. (1990). Family adaptation to childhood cancer: Sibling and family systems variables. Journal of Clinical Child Psychology, 19, 221-228.

Hoven, C. W., Duarte, C. S., Lucas, C. P., Wu, P., Mandell, D. J., Goodwin, R. D., . . Susser, E. (2005). Psychopathology among New York city public school children 6 months after September 11. Archives of General Psychiatry, 62, 545-552.

Huizinga, G. A., Visser, A., van der Graaf, W. T., Hoekstra, H. J., Gazendam-Donofrio, S. M., \& Hoekstra-Weebers, J. E. (2010). Stress response symptoms in adolescents during the first year after a parent's cancer diagnosis. Supportive Care in Cancer, 18, 1421-1428.

Kazak, A. E., Christakis, D., Alderfer, M., \& Coiro, M. J. (1994). Young adolescent cancer survivors and their parents: Adjustment, learning problems, and gender. Journal of Family Psychology, 8, 74-84.

Kazak, A. E., \& Meadows, A. T. (1989). Families of young adolescents who have survived cancer: Social-emotional adjustment, adaptability, and social support. Journal of Pediatric Psychology, 14, 175-191. 
Korneluk, Y. G., \& Lee, C. M. (1998). Children's adjustment to parental physical illness. Clinical Child and Family Psychology Review, 1, 179-193.

Lerman, C., Daly, M., Sands, C., Balshem, A., Lustbader, E., Heggan, T., . . Engstrom, P. (1993). Mammography adherence and psychological distress among women at risk for breast cancer. Journal of the National Cancer Institute, 85, 1074-1080.

Lewandowski, L. A. (1992). Needs of children during the critical illness of a parent or sibling. Critical Care Nursing Clinics of North America, 4, 573-585.

Lindberg, N. M., \& Wellisch, D. K. (2004). Identification of traumatic stress reactions in women at increased risk for breast cancer. Psychosomatics, 45, 7-16.

Manne, S. L., Lesanics, D., Meyers, P., Wollner, N., Steinherz, P., \& Redd, W. (1995). Predictors of depressive symptomatology among parents of newly diagnosed children with cancer. Journal of Pediatric Psychology, 20, 491-510.

Marsac, M. L., \& Alderfer, M. A. (2011). Psychometric properties of the FACES-IV in a pediatric oncology population. Journal of Pediatric Psychology, 36, 528-538.

Mirnics, Z., Vargha, A., Tóth, M., \& Bagdy, E. (2010). Cross-cultural applicability of FACES IV. Journal of Family Psychotherapy, 21, 17-33.

Mosher, C. E., \& Danoff-Burg, S. (2005). Psychosocial impact of parental cancer in adulthood: A conceptual and empirical review. Clinical Psychology Review, 25, 365-382.

Navia, C. E., \& Ossa, M. (2003). Family functioning, coping, and psychological adjustment in victims and their families following kidnapping. Journal of Traumatic Stress, 16, 107-1 12.

Nunnally, J., \& Bernstein, I. (1994). Psychometric theory (3rd ed.). New York, NY: McGraw-Hill.

Olson, D. H. (1993). Circumplex model of marital and family systems: Assessing family functioning. In F. Walsh (Ed.), Normal family processes (2nd ed., pp. 104-137). New York, NY: Guilford.

Olson, D. H. (2000). Circumplex model of marital and family systems. Journal of Family Therapy, $22,144-167$.

Olson, D. H. (2004). Family Satisfaction Scale (FSS). Minneapolis, MN: Life Innovations.

Olson, D. H. (2010). Data analysis using FACES-IV scores. Minneapolis, MN: Life Innovations.

Olson, D. H. (2011). FACES IV and the Circumplex model: Validation study. Journal of Marital and Family Therapy, 37, 64-80.

Olson, D. H., \& Barnes, H. (2004). Family Communication Scale. Minneapolis, MN: Life Innovations.

Owen, A., Thompson, M., Shaffer, A., Jackson, E., \& Kaslow, N. (2009). Family variables that mediate the relation between intimate partner violence (IPV) and child adjustment. Journal of Family Violence, 24, 433-445.

Ozono, S., Saeki, T., Mantani, T., Ogata, A., Okamura, H., \& Yamawaki, S. (2007). Factors related to posttraumatic stress in adolescent survivors of childhood cancer and their parents. Supportive Care in Cancer, 15, 309-317.

Pelcovitz, D., Libov, B. G., Mandel, F., Kaplan, S., Weinblatt, M., \& Septimus, A. (1998). Posttraumatic stress disorder and family functioning in adolescent cancer. Journal of Traumatic Stress, 11, 205-221.

Pereira, M. G., \& Teixeira, R. J. (2011). Portuguese validation of the Impact of Event ScaleRevised (IES-R) in adult children of cancer patients. Psycho-oncology, 20(Suppl. 2), 146.

Pinquart, M., \& Sörensen, S. (2003). Associations of stressors and uplifts of caregiving with caregiver burden and depressive mood: A meta-analysis. The Journals of Gerontology. Series B, Psychological Sciences and Social Sciences, 58(2), P112-P128.

Preacher, K. J., \& Kelley, K. (2011). Effect size measures for mediation models: Quantitative strategies for communicating indirect effects. Psychological Methods, 16, 93-115.

Preacher, K. J., \& Hayes, A. F. (2004). SPSS and SAS procedures for estimating indirect effects in simple mediation models. Behavior Research Methods, Instruments, \& Computers, 36, 717-731. 
Rutledge, C. M., Davies, S. M., \& Davies, T. C. (1994). Family dysfunction and the well-being of medical students. Family Systems Medicine, 12, 197-204.

Schulz, K. H., Schultz, H., Schultz, O., \& Von Kerekjarto, M. (1996). Family structure and psychosocial stress in families of cancer patients. In L. Baider, C. L. Cooper, \& A. Kaplan De-Nour (Eds.), Cancer and the family (pp. 226-255). New York, NY: Wiley.

Shemesh, E., Newcorn, J. H., Rockmore, L., Shneider, B. L., Emre, S., Gelb, B. D., . . Yehuda, R. (2005). Comparison of parent and child reports of emotional trauma symptoms in pediatric outpatient settings. Pediatrics, 115, e582-e589.

Trask, P. C., Paterson, A. G., Trask, C. L., Bares, C. B., Birt, J., \& Maan, C. (2003). Parent and adolescent adjustment to pediatric cancer: Associations with coping, social support, and family function. Journal of Pediatric Oncology Nursing, 20, 36-47.

Uruk, A. C., Sayger, T. V., \& Cogdal, P. A. (2007). Examining the influence of family cohesion and adaptability on trauma symptoms and psychological well-being. Journal of College Student Psychotherapy, 22, 51-63.

Vanderlinden, J., \& Vandereycken, W. (2000). Mediating factors between trauma and dissociation in eating disorders. In L. Sanchez-Planell \& C. Diez-Quevedo (Eds.), Dissociative states (pp. 75-85). Berlin, Germany: Springer-Verlag Iberica.

Wang, L., Zhang, J., Shi, Z., Zhou, M., Huang, D., \& Liu, P. (2011). Confirmatory factor analysis of posttraumatic stress symptoms assessed by the Impact of Event Scale-Revised in Chinese earthquake victims: Examining factor structure and its stability across sex. Journal of Anxiety Disorders, 25, 369-375.

Warner, V., Mufson, L., \& Weissman, M. M. (1995). Offspring at high and low risk for depression and anxiety: Mechanisms of psychiatric disorder. Journal of the American Academy of Child and Adolescent Psychiatry, 34, 786-797.

Weihs, K., \& Reiss, D. (1996). Family reorganization in response to cancer: A developmental perspective. In L. Baider, C. L. Cooper, \& A. Kaplan De-Nour (Eds.), Cancer and the family (pp. 3-30). New York, NY: Wiley.

Weiss, D., \& Marmar, C. (1997). The Impact of Event Scale-Revised. In J. P. Wilson \& T. M. Keane (Eds.), Assessing psychological trauma and PTSD: A practitioner's handbook (pp. 399-411). New York, NY: Guilford Press.

Wong, M., Looney, E., Michaels, J., Palesh, O., \& Koopman, C. (2006). A preliminary study of peritraumatic dissociation, social support, and coping in relation to posttraumatic stress symptoms for a parent's cancer. Psycho-oncology, 15, 1093-1098.

Zakowski, S. G., Valdimarsdottir, H. B., Bovbjerg, D. H., Borgen, P., Holland, J., Kash, K., . . . Van Zee, K. (1997). Predictors of intrusive thoughts and avoidance in women with family histories of breast cancer. Annals of Behavioral Medicine, 19, 362-369.

Acknowledgment. This research was supported by a grant (SFRH/BD/43275/2008) awarded to the first author (RJT) by the Portuguese Foundation for Science and Technology.

All procedures followed were in accordance with the ethical standards of the responsible committee on human experimentation of three Portuguese general hospitals (Portuguese Institute of Oncology-Porto, Hospital Pedro Hispano, and Hospital de S. Marcos), a Portuguese state university (University of Minho), and with the Helsinki Declaration of 1975, as revised in 2000. Informed consent was obtained from all patients for being included in the study.

Correspondence regarding this article should be directed to Ricardo J. Teixeira, PhD, University of Minho, School of Psychology, Campus de Gualtar, 4710-057 Braga, Portugal. E-mail: ricardojft@gmail.com 